\title{
28
}

\section{Community-Based Research: Learning About Attitudes Towards the Criminal Justice System}

\author{
Tammy A. Marche \& Jennifer L. Briere \\ University of Saskatchewan
}

Research points to the pedagogical value of an engaged and community service-learning approach to developing understanding of course content (Astin, Vogelgesang, Ikeda, \& Yee, 2000). To help students achieve a better understanding of how the discipline of psychology contributes to the discipline of law, some students in a second year psychology class participated in a community-based research project, partnering with the Elizabeth Fry Society and the John Howard Society. The objective of the study was to determine whether there are differences in attitudes towards the criminal justice system between individuals who have, and have not, been in conflict with the law. The student-researchers interviewed men and women from the John Howard and Elizabeth Fry Societies, who had been in conflict with the law, regarding their attitudes toward the criminal justice system, and compared their responses to those given by undergraduate psychology students who did not participate as student-researchers in the project. Responses revealed some commonalities (e.g., recommendations to change sentencing practices) as well as differences (e.g., satisfaction with the justice system). The students wrote a research report describing the findings of the study as well as their reflections on their experience. In addition to the positive feedback received from the community organizations, the students participating in the project reported that they found it to be a positive, enriching, and rewarding experience.

\section{Introduction}

$\mathrm{T}$ he objective of this paper is to demonstrate how instructors can facilitate students' understanding of course material by partnering with communitybased organizations on research projects that benefit both students and community organizations.
With a 40-year history, the service-learning teaching strategy takes students' learning outside of the classroom and into the community (Beatty, 2010). Jacoby (1996) defines service learning as "a form of experiential education in which students engage in activities that address human and community needs together with structured opportunities 
intentionally designed to promote student learning and development" (p. 5). Community-based research is a collaboration between academic researchers (professors and students) and community members that seeks to solve a pressing community problem and/or effect social change and social justice (Strand, Marullo, Cutforth, Stoecker, \& Donohue, 2003). These mutually beneficial partnerships between students and community organizations promote students' understanding of course content and often result in positive academic outcomes (Astin, Vogelgesang, Ikeda, \& Yee, 2000).

To help students better understand how psychology contributes to the criminal justice system, and to gain hands-on experience of the Canadian justice system, students enrolled in a second-year psychology course, Psychology and Law, participated in a research project in partnership with the local chapters of the Elizabeth Fry Society and the John Howard Society. Both organizations work to enhance the dignity of men (John Howard Society) and women (Elizabeth Fry Society) who are, or who may be at risk of becoming, criminalized. Both societies advocate for effective and just changes in the criminal justice system, and educate the public on issues related to the criminal justice process.

Using interview-style data collection, the project examined whether there were differences in attitudes towards the criminal justice system between undergraduate students and individuals who had been in conflict with the law. Students read papers describing background literature on the research topic. They learned that by determining where differences in attitudes exist, ways of increasing satisfaction and confidence in the justice system can be identified, and that public support is necessary for the system to work effectively (e.g., Indermaur \& Hough, 2002; Roberts, 2004; Tyler \& Huo, 2002).

\section{Project Method}

To ensure that students had sufficient background and experience to carry out the project, those interested in participating as student-researchers submitted a statement of interest. This statement included a description of prior research methods courses, previous experiences with using psychological research methods, and previous community service learning and volunteer experiences. All students met these requirements. They then received instruction in ethics (e.g., data confidentiality and procedures for obtaining informed consent, debriefing, and participant withdrawal) and guidelines for data collection for the project via handouts, participation in a group meeting and by online ethics tutorials. The students and instructor also met with representatives from the community agencies to learn about the organizations and their expectations regarding data collection. The agencies were responsible for recruiting participants who had been in conflict with the law and the interviews took place at their facility during a mutually agreed time. In some cases, the agency hosted a small social before commencing the interviews. Students taking the Psychology and Law class were asked to answer the same interview questions as did the participants who had been in conflict with the law. Participants from the organizations were given a small financial gift of thanks after the interviews, which they were unaware of at the time of the interview, whereas there was no reward for the student participants. After the interviews, the students submitted all data forms to the instructor to be scored and analyzed. Students were then provided with a write-up of the results, along with a brief interpretation of the statistical findings. They were expected to write an 8-page term paper describing the study results and their reflections on the project.

\section{Study Method}

\section{Participants}

Over four offerings of the Psychology and Law course, 28 student-researchers (27 females; 1 male) conducted interviews with 33 individuals who had been in conflict with the law (19 females, $M_{\text {age }}=35$, range: $21-48$ years; 14 males, $M_{\text {age }}=31$, range: 22 53 years). In addition, 71 undergraduates, who were mostly Arts and Science students (60 females, 11 males; $M_{\text {age }}=22$, range: $19-42$ years), served as 
the comparison group by responding to the same interview questions. Sixty-two undergraduates were of European/Caucasian decent with the remaining undergraduates being of First Nations/Métis, East Indian, Asian, Central American, or other decent. The majority of both the females $(n=12)$ and males $(n=11)$ who had been in conflict with the law, for primarily serious offenses, were of First Nations/ Métis decent, followed by East Indian (females $n$ $=3$, males $n=2$ ), and European/Caucasian decent (females $n=3$, males $n=1$ ).

\section{Measures and procedure}

The interview was based on four questionnaires that assessed confidence and satisfaction in the criminal justice system as well as attitudes towards sentencing practices and the criminal justice system overall. After consent forms were signed, the student-researchers interviewed either a male or female participant who had been in conflict with the law. Questions were read aloud to participants, due to literacy concerns, as the participants followed along on their own copies and the student-researchers recorded the responses. To collect the undergraduate responses, hard-copies of each of the four questionnaires, as well as consent forms, were distributed to the students during regular class time. The second author read the questions to the students, in an interview-like format, and they recorded their own responses.

Participants completed the Confidence in the Criminal Justice System (Tufts, 2000) measurur, which includes six questions that are answered using a 5-point scale ranging from 1 = "Not at all confident" to 5 = "Extremely confident" (e.g., "Please rate your confidence in the local police service.”). Participants' satisfaction was assessed with Satisfaction with the Criminal Justice System (Tufts, 2000), a 5-point scale ranging from 1 = "Strongly Disagree" to 5 = "Strongly Agree" 10 questions, e.g., "The courts do a good job of ensuring a fair trial for the accused."). Participants also completed the Attitudes Towards the Criminal Justice System scale (25 questions, e.g., "Laws are usually bad."), which is a sub-scale of the Criminal Sentiments Scale (CSS, Andrews \& Wormith, 1984), and Attitudes Towards Sentencing Practices (Tanasichuk, 20105 questions using a 5-point scale, with 1 = "Too Harsh" to 5 = "Too Lenient"; e.g., "Do you feel that sentences given to female offenders are too lenient, too harsh or just about right?"). Participants were also asked to respond to the openended question: "How do you think confidence in the criminal justice system could be increased?"

Participants were thanked and debriefed; any questions that they had were addressed by either the student-researchers or the course instructor.

\section{Study Results}

Undergraduates reported significantly more confidence in the criminal justice system $(M=21.41$, $S D=3.41)$ than individuals who have been in conflict with the law $(M=16.44, S D=3.96), t(100)=6.50$, $p<.001$. Undergraduates also reported significantly greater satisfaction with the criminal justice system $(M=30.23, S D=4.89)$ than did individuals in conflict with the law $(M=25.35, S D=6.89), t$ $(99)=4.06, p<.001$. Additionally, undergraduates reported significantly more positive attitudes towards the criminal justice system $(M=89.26, S D=10.26)$ than people who have been in conflict with the law $(M=76.96, S D=12.03), t(93)=4.97, p<.001$. In terms of attitudes towards sentencing practices, the difference between the undergraduates $(M=19.13$, $S D=2.80)$ and individuals in conflict with the law $(M=17.66, S D=3.12)$ approached significance when the Bonferonni correction to control for Type I error was applied $(\alpha=.01), t(94)=2.30, p=.02$.

Although we found that undergraduates and individuals who have been in conflict with the law appeared to differ in terms of some of the responses they gave to the open-ended question "How do you think confidence in the criminal justice system could be increased?," a number of common themes emerged across both groups. For example, individuals who had been in conflict with the law and undergraduate students both indicated rehabilitation (more programs to minimize reoffending) as a means to increase confidence in the criminal justice system. Also, male and female participants who had been in conflict with the law both agreed that prevention programs need to target youth in order to prevent 
involvement in the criminal justice system. See Table 1 for more examples.

\section{Summary and Conclusions}

As part of the research report write-up, the studentresearchers spent time reflecting on why attitudinal differences exist between these two groups and they argued that actions need to be taken to improve confidence and satisfaction in the criminal justice system to ensure its effectiveness, highlighting some of the responses made by the participants (Table 1). They also commented on the similarities found across the two groups (e.g., the need to change sentencing practices). These findings were reported to all students in each of the four offerings of Psychology and Law classes in a lecture discussing the relationship (linkages and tensions) between criminal justice and social justice. The participating students informally reported their experiences and reflections to the class and we discussed ways in which the justice system can become more responsive to the local communities and national agencies with which it interacts.

Many studies have examined the benefits that engaging in community-based learning has for students, faculty, universities and communities (e.g., Eyler, Giles, Gray, \& Stenson, 2001). Students in the current project reported a number of personal outcomes (e.g., enhancing personal identity, moral development, interpersonal development), social outcomes (e.g., reducing stereotypes, increasing a sense of social responsibility), and learning outcomes (e.g., improved ability to apply what they are learning to the real world). The student-researchers, and especially the Psychology and Law students who did not participate, initially reported knowing nothing about the community partners, with many students reporting that they had never heard of the organizations. A description of each organization, illustrated with the content on each organization's website, was provided to all students during the class lecture on social justice. Thus, similar to other service learning programs (e.g., Lane, Hudson, McCray, Tragash, \& Zeig, 2011), the student-researchers found the project to be a positive, enriching and

TABLE 1

Themes from the question "How do you think confidence in the criminal justice system could be increased?"

\section{Group}

Theme

Undergraduates

(a) Change the court system.

(b) Respond to all inquiries similarly.

(c) Gain public input.

(d) Change the information that the media shares about the criminal justice system.

\section{Individuals in Conflict with the Law}

(a) Ensuring confidentiality.

(b) Involve family.

(c) Direct money towards community resources.

(d) Change the jails.

(e) Include aboriginal culture.

\section{Response Example}

(a) "Ensuring a speedy trial,"

(b) "Respond to all inquiries in the same way,"

(c) "Public voting on punishment for crime (in general, not for a specific case)."

(d) "Media attention on good things police, corrections and law enforcement provide."

(a) "Police tell you they won't use information you tell them against you, but they do."

(b) "Involve family more."

(c) "More money to help community, direct behavior away from negative."

(d) "Jails are not run effectively, dirty grounds,"

(e) "Incorporate the aboriginal justice system into it." 
rewarding experience that augmented the skills and knowledge learned in the classroom. As the following quotes attest, the community service learning project enriched students' experiences.

"I think it should be mandatory for all students to do more research based work within the community. Not only does it help students to better understand their subject, but it also allows you to help out the community."

"An important element of the community service-learning experience was having an opportunity to apply the knowledge we learned in class out into the community. Integrating 'real life' knowledge and experiences directly from people in conflict with the law with classroom based knowledge made it a more enriching experience and supported learning on a multidimensional level."

"I was able to compare and contrast what I learned in class versus what I discovered in the community."

The project also appeared to affect some students well after the course had ended. For example, one of the students, because of her experience with the project, subsequently secured summer employment with the Elizabeth Fry Society and, in the subsequent school year, worked on a justice-related honours thesis.

As a faculty member, this project provided the first author with the opportunity to learn about community service learning and to improve teaching pedagogy, as well as enhance understanding of social justice issues. As for benefits to the community organizations, members of the organizations have consistently reported that the project provides their clients with an opportunity to have their voices heard. Some of the men and women reported that this was the first time anyone had asked about their experiences or had taken an interest in their opinions.
Partnering with the University may also provide other research opportunities, which have the potential to benefit both the staff and clients from community organizations.

The community agencies were presented with a written description of the results of the study, and a copy of the current paper. They have also been invited to help design the next research project. During the coming year, we plan to increase the community agencies' role in the project as we move toward developing the next community-based research project, one that aims to achieve social change and social justice.

\section{References}

Andrews, D. A., \& Wormith, J. S. (1984). The Criminal Sentiments Scale. Ottoawa, ON: Ministry of Correctional Services of Canada.

Astin, A.W., Vogelgesang, L.J., Ikeda, E.K., \& Yee, J.A. (2000). How service learning affects students. Los Angeles: Higher Education Research Institute, UCLA.

Beatty, J.E. (2010). For which future? Exploring the implicit futures of service-learning. International Journal of Organizational Analysis, 18, 181-197.

Eyler, J.S., Giles, D.E., Gray, C.J., \& Stenson, C.M. (2001). At a glance: What we know about the effects of service-learning on college students, faculty, institutions and communities, 1993-2000: Third edition. Nashville, TN: Vanderbilt University.

Indermaur, D. \& Hough, M. (2002). Strategies for changing public attitudes to punishment. In J.V. Roberts \& M. Hough (Eds.), Changing attitudes to punishment: Public opinion, crime and justice (pp. 1-14). Portland, OR: Willan Publishing.

Jacoby, B. \& Associates. (1996). Service-learning 
in higher education: Concepts and practices. Jossey-Bass Publishers: San Francisco.

Lane, H.B., Hudson, R.F., McCray, E.D., Tragash, J.R., \& Zeig, J.L. (2011). Tutoring opened my eyes: Tutor experiences in the America reads challenge. Mentoring \& Tutoring: Partnership in Learning, 19, 199-218.

Roberts, J. (2004). Public confidence in criminal justice: A review of recent trends, 2004-05. A report for Public Safety and Emergency Preparedness Canada. Retrieved from http:// www.publicsafety.gc.ca/res/cor/rep/2004-05pub-conf-eng.aspx

Strand, K., Marullo, S., Cutforth, N., Stoecker, R., \& Donohue, P. (2003). Principles of best practice for community-based research. Michigan Journal of Community-Service Learning, 5-15. Retrieved from http://hdl. handle.net/2027/spo.3239521.0009.301

Tenasichuk, C. A. (2010). Increasing confidence in the criminal justice system through public education. Electronic Thesis \& Dissertation, University of Saskathcewan, Saskatoon, SK. (URN No. edt-11172010-172342).

Tufts, J. (2000). Public attitudes toward the Criminal Justice System. Juristat, 20(12), 2-22.

Tyler, T.R. \& Huo, Y.J. (2002). Trust in the law: Encouraging public cooperation with the police and courts. New York, NY: Russell Sage.

\section{Biography}

Tammy A. Marche is an Associate Professor at St. Thomas More College, University of Saskatchewan. Tammy's interests are in the forensic aspects of memory and she is a member of the Centre for Behavioral Sciences and Justice Studies, University of Saskatchewan.
Jennifer L. Briere is a Ph.D. candidate in the Psychology Department at the University of Saskatchewan and was the Research Assistant for this project. 